\title{
Wind chop and ship wakes determine hydrodynamic stresses on larvae settling on different microhabitats in fouling communities
}

\author{
M. A. R. Koehl ${ }^{1, *}$, J. P. Crimaldi' ${ }^{2}$, D. E. Dombroski ${ }^{2}$ \\ ${ }^{1}$ Department of Integrative Biology, University of California, 3060 VLSB, Berkeley, California 94720-3140, USA \\ ${ }^{2}$ Department of Civil, Environmental and Architectural Engineering, University of Colorado, 428 UCB, Boulder, \\ Colorado 80309-0428, USA
}

\begin{abstract}
Fouling communities living on hard surfaces in harbors are model systems for studying larval recruitment and ecological succession. Although they live in protected harbors, fouling communities are exposed to waves due to wind chop and ship wakes. We studied how superimposing waves onto unidirectional currents affects hydrodynamic stresses experienced by larvae settling into different microhabitats within rugose fouling communities. We exposed fouled plates in a flume to turbulent water currents and waves mimicking those measured across fouling communities in Pearl Harbor, Hawaii, USA, and used laser-Doppler velocimetry to measure water velocities on the scale of larvae (500 $\mu \mathrm{m}$ from surfaces) at specific positions within each community chosen to represent a wide range of microhabitat types. These data were used to determine instantaneous hydrodynamic stresses encountered by larvae and to calculate larval settlement probabilities. Local topography was more important than successional stage in determining hydrodynamic stresses on the scale of larvae. Increasing current velocity reduced settlement probabilities, with the largest effects on a flat unfouled surface and on microhabitats on the tops of fouling organisms. Wind chop and ship wakes reduced the probability of larval settlement at all current speeds and in all microhabitats, with the most pronounced effects on sites atop fouling organisms. Episodic peak stresses can be orders of magnitude higher than mean stresses, so using instantaneous stresses to calculate settlement probability yields a lower value than is predicted using mean stress. The factor by which the use of mean stress over-estimates settlement probability depends on both microhabitat and flow conditions.
\end{abstract}

KEY WORDS: Larval settlement $\cdot$ Biofouling $\cdot$ Reynolds stress $\cdot$ Turbulence $\cdot$ Waves $\cdot$ Microhabitat Boundary layer

\section{INTRODUCTION}

The assemblages of organisms living on hard surfaces in estuaries and harbors ('fouling communities') have long served as model systems for studying ecological succession, the processes by which communities are established and develop over time (e.g. Sutherland \& Karlson 1977). Most of the organisms in marine fouling communities are sessile invertebrates that produce planktonic larvae, which are trans- ported by ambient currents and colonize new surfaces. The recruitment of larvae to benthic sites is a critical process affecting community structure (reviewed by Ólafsson et al. 1994, Schiel 2004, Edwards \& Stachowicz 2011). To colonize a surface, a larva must be transported to that surface, settle (i.e. attach to the surface), and recruit (i.e. metamorphose into a juvenile and survive) (Keough \& Downes 1982). The successional stage of a fouling community can affect larval settlement into the community for some spe- 
cies, but not for others (e.g. Hurlbut 1991, Walters et al. 1999, Miron et al. 2000).

Although mean current velocities in harbors are typically low, measurements of water velocity as a function of time near fouling communities on docks revealed that instantaneous velocities can be much higher due to turbulence and waves (both wind chop and the wakes of boats and ships) (Okamura 1984, Hunter 1988, Schabes 1992, Koehl \& Reidenbach 2007, Koehl \& Hadfield 2010). The purpose of the study reported here was to explore how small waves (wind chop) and larger waves (ship wakes) superimposed on slow ambient currents affect the local hydrodynamic stresses experienced by microscopic larvae settling onto different microhabitats within fouling communities.

Many studies have focused on how water flow in the benthic boundary layer (the layer of water in which the velocity gradient between the substratum and free-stream ambient flow occurs) affects the transport of larvae to the bottom in unidirectional currents (e.g. reviewed in Butman 1990, Eckman et al. 1994, Ableson \& Denny 1997, Koehl 2007), and a few studies have considered the effects of turbulence on the transport of larvae to the substratum (reviewed in Fuchs et al. 2007, 2010, Koehl 2007, Zilman et al. 2008, Lillis \& Snelgrove 2010). To complement that body of work on transport of larvae to the substratum, the present study focuses on the process of settlement by larvae that have already arrived at a surface. The hydrodynamic stresses experienced by a larva as it settles onto a surface depend on the instantaneous water flow (spatial scale of hundreds of microns) directly above a potential settlement site. Therefore, we explored the effects of ambient current velocity and waves on the probability of larval settlement onto a variety of different microhabitats within the complex topography of animals living in fouling communities at different successional stages.

\section{Water flow affects larval settlement}

Experiments in the field and in laboratory flumes, as well as mathematical models, have shown that water motion in the benthic boundary layer not only affects larval transport, but also influences the settlement of larvae onto surfaces (e.g. reviewed by Butman 1990, Eckman et al. 1994, Abelson \& Denny 1997, Crimaldi et al. 2002, Koehl \& Hadfield 2004, Larsson \& Jonsson 2006, Koehl 2007, Koehl \& Reidenbach 2007, Koehl \& Hadfield 2010). Ambient water motion can affect larval settlement (i.e. larval exploration of and attachment to a surface) in a number of ways. Some types of larvae actively move around on surfaces after they land and choose the spot on which to settle, but ambient currents can alter or prevent that exploratory behavior (e.g. Butman 1990, Mullineaux \& Butman 1991, Lindegarth et al. 2002, Pernet et al. 2003, Jonsson et al. 2004, Kobak 2005, Dobretsov \& Wahl 2008). Hydrodynamic forces can also wash settling larvae off surfaces (e.g. Crisp 1955, Abelson et al. 1994, Abelson \& Denny 1997, Jonsson et al. 2004, Koehl \& Hadfield 2004, Koehl 2010).

In turbulent flow, high instantaneous shear stresses occur along surfaces when eddies 'sweep' through the slowly moving water next to the surface and water near the surface 'bursts' up into the overlying flow (e.g. Eckman et al. 1990, Abelson \& Denny 1997, Crimaldi et al. 2002, Reidenbach et al. 2009). Such instantaneous peaks in hydrodynamic force on settling larvae can affect their probability of anchoring (Crimaldi et al. 2002, Reidenbach et al. 2009).

In spite of the importance of waves in shallow coastal habitats, most studies of flow effects on larval settlement have focused on unidirectional currents. A few mathematical models have explored the consequences of waves on the transport of larvae or spores to the substratum (e.g. Denny \& Shibata 1989, Gross et al. 1992, Koehl \& Reidenbach 2007, Koehl et al. 2007, Stevens et al. 2008, Koehl \& Hadfield 2010), but not on the post-contact adhesion to surfaces. Waves should affect larval settlement, since shear stresses along the bottom are higher in waves, which are more effective at washing particles off surfaces than is unidirectional flow at the same free-stream velocity (e.g. Koehl 1977, Denny 1988, Koehl \& Hadfield 2004). Rittschof et al. (2007) suggested that the rocking of floating docks in waves might be responsible for deviations of larval settlement patterns from those predicted using mean flow velocities past the docks.

\section{Small-scale topography affects larval settlement}

Surface topography affects settlement rates of the larvae of many species, including a variety of ascidians, barnacles, crabs, polychaetes, bryozoans, hydroids, and sponges (reviewed by Koehl 2007, Prendergast et al. 2009, Scardino et al. 2009, Fingerut et al. 2011). Where larvae settle on rough surfaces exposed to moving water depends on species, some preferentially settling in grooves or pits, and around the bases of bumps or attached organisms (Chabot \& 
Bourget 1988, LeTourneux \& Bourget 1988, Walters \& Wethey 1991, 1996, Walters 1992a,b, Moldonado \& Uriz 1998, Underwood 2004, Kobak 2005), versus others settling on the peaks of bumps (Chabot \& Bourget 1988, LeTourneux \& Bourget 1988, Walters \& Wethey 1991, Miron et al. 1996). Mounting evidence that the interaction of water flow with surface roughness affects larval settlement (reviewed in Abelson \& Denny 1997, Koehl 2007) indicates that a detailed analysis of the small-scale hydrodynamics encountered by microscopic larvae in different types of topographic microhabitats within communities of benthic organisms is an essential component of elucidating the mechanisms affecting where larvae settle.

\section{Flume studies of small-scale flow near rough surfaces}

Larvae settling from a dynamic fluid onto a static substratum experience hydrodynamic stresses that may impede the larvae's ability to come to rest (e.g. Abelson \& Denny 1997). For steady, laminar flows, these stresses are due only to viscous effects. This viscous shear stress is proportional to the velocity gradient, which is largest at the substratum. For turbulent flows, additional apparent stresses (Reynolds stresses) are present (Allen 1985). The instantaneous turbulent Reynolds stress at a point is $\tau=-\rho u w$, where $u$ and $w$ are the streamwise and vertical velocities, respectively, and $\rho$ is the fluid density. The turbulent velocities in the streamwise and vertical directions can each be decomposed into the sum of mean values ( $U$ and $W$, respectively), and time-varying fluctuations away from the mean $\left(u^{\prime}\right.$ and $\left.w^{\prime}\right)$. Using this decomposition, and noting that $W \approx 0$ near the substratum, $\tau$ near the bed becomes:

$$
\tau=-\rho u w^{\prime}-u^{\prime} w^{\prime}
$$

The time-averaged Reynolds stress then becomes simply the correlation between the fluctuating velocities $-\overline{u^{\prime} w^{\prime}}$. Near the substratum in a turbulent flow, both viscous and turbulent stresses are present. For flows over relatively smooth surfaces, viscous stresses dominate turbulent stresses in an extremely thin layer next to the surface called the viscous sublayer. Outside this layer, and in all locations for flows over rough surfaces, turbulent stresses dominate.

Predicting all of the instantaneous constituent forces (e.g. lift, drag, acceleration reaction) and moments of force associated with the hydrodynamic stresses acting on a larva on a surface is complex. The magnitudes of the various forces depend on the morphology and orientation of the larva, the character of the bed and a larva's location in it, and the flow state (e.g. Koehl 2007, 2010). However, at the larval scale, the temporal variation of the hydrodynamic forces depends only on the temporal variation of the local velocity field, i.e. the local turbulence structure. The temporal character of the Reynolds stress should indicate the temporal character of all of the hydrodynamic forces acting on a settling larva. Therefore, we chose (following Crimaldi et al. 2002) to study the Reynolds stresses because: (1) they are typically large in turbulent boundary layer flows and (2) they are easily measured in the laboratory using nonintrusive measurement techniques.

Microscopic larvae settling onto surfaces on which macroscopic organisms are living experience water flow that is affected by the presence of those organisms. Turbulent boundary layers over smooth surfaces have complex instantaneous flow patterns with well-defined mean statistical distributions of flow properties (e.g. Ligrani 1989). Turbulent flows over rough beds gain additional complexity. Of particular relevance to this study is that flows over rough surfaces have more violent ejections away from the wall (Grass 1971) and shorter average times between large Reynolds stress events than do flows over smooth surfaces (Krogstad et al. 1992). These effects of bed roughness are enhanced in waves (Grant \& Madsen 1986). However, bed roughness complicates the ability to make statistical generalizations about turbulence structure, which is sensitive to the details of the particular roughness type (Carpenter 1997). Flows over complex types of roughness such as gravel beds or plant canopies (e.g. Mulhearn \& Finnigan 1978, Ghisalberti 2009) are well studied, but the turbulence statistics very close to such surfaces become spatially variable due to the local differences in fine-scale topography (e.g. Friedrichs \& Graf 2009, Reidenbach et al. 2009). At the small scales relevant to the larval settling process, local flow patterns around individual roughness elements should be considered along with flow over the aggregate bed roughness.

The sizes, shapes, and spacing of attached organisms (roughness elements) in fouling communities are diverse and change as fouling communities develop. Therefore, fouling communities provide a good system for exploring the effects of local smallscale topography on the flow microhabitats into which larvae might settle. For example, a larva landing on a smooth, flat surface might experience different hydrodynamic forces than a larva landing in a crevice between barnacles or on top of an oyster. 


\section{Objectives of this study}

The purpose of our study was to determine the instantaneous hydrodynamic stresses that would be encountered by larvae settling on fouling communities exposed to realistic harbor flow conditions. Our specific objectives were to determine the effects of the following parameters on the probability of larval settlement: (1) local small-scale topography, (2) current speed, (3) waves due to wind chop and to ship wakes, and (4) the time required for larvae to adhere to the substratum.

We addressed these issues using the fouling community in Pearl Harbor, Hawaii, USA. The conspicuous animals in this community include the tubebuilding serpulid polychaetes Hydroides elegans, encrusting bryozoans Schizoporella unicornis, barnacles Balanus eburneus, oysters Anomia nobilis, a number of species of sponges, and a variety of ascidians (e.g. the solitary tunicate Phallusia nigra) (Hurlbut 1991, M. G. Hadfield pers. comm.). Hurlbut (1991) studied the succession of this community on plates in Pearl Harbor and found that free space on the plates decreased and the surface relief of the community increased with time as settlers accumulated and grew. She also observed that $H$. elegans and $S$. unicornis preferentially colonized next to other animals already growing on the plates.

\section{MATERIALS AND METHODS}

We measured the instantaneous water velocities on the spatial scale relevant to settling larvae $(500 \mu \mathrm{m}$ from a surface) for a range of different microhabitat types within fouling communities when they were exposed in a laboratory flume to realistic harbor flow regimes with and without waves. We used these data to calculate the probabilities of attachment onto those surfaces by larvae with different anchoring times.

\section{Settling plates}

Steel plates $(31 \mathrm{~cm} \times 16 \mathrm{~cm})$ were coated with various types of paint and were then suspended from a dock on Ford Island in Pearl Harbor, Oahu, Hawaii. The communities of organisms that developed on the plates coated with some types of anti-fouling paints developed slowly and were characterized by the encrusting bryozoans Schizoporella unicornis and small tube worms Hydroides elegans, showing the low profiles characteristic of fouling communities at an early stage of succession (Fig. 1a,b). In contrast, the assemblages of organisms that developed on other plates were typical later-stage fouling communities characterized by a variety of larger organisms in addition to the bryozoans and tube worms (Fig. 1c,d). The large organisms included the barnacles Balanus eburneus, oysters Anomia nobilis, solitary ascidians Phallusia nigra, compound ascidians (e.g. Diplosoma spp., Didemnum candidum), and various species of sponges. We chose 1 plate with a fouling community at an early successional stage ('early'; Fig. 1a) and 1 plate with a fouling community at a late successional stage ('late'; Fig. 1c) for our experiments so that we could study examples of microhabitats with very different types of local fine-scale topography.

The fouled plates were frozen and kept in dry air at less than $-1.0^{\circ} \mathrm{C}$ for a month, until the water in the fouling organisms had sublimed away. After thawing, the freeze-dried fouling communities on the plates were spray-painted with 3 coats of matte black paint (Rustoleum) to waterproof the organisms and minimize reflection of the laser light from their surfaces (Fig. 1). We determined the elevations of selected positions on each plate using a micrometer. Five replicates of each height measurement were made; they were repeatable to the nearest $0.01 \mathrm{~mm}$. We also prepared an unfouled plate ('smooth') with a smooth painted surface and measured the height of the midpoint of that plate.

\section{Flume}

The laboratory experiments were conducted in a recirculating flume at the University of Colorado with a test section that was $9 \mathrm{~m}$ long, $1.25 \mathrm{~m}$ wide, and had a nominal flow depth of $0.3 \mathrm{~m}$. A turbulent boundary layer formed along the bed of the test section for all flow conditions used in the study. To ensure a consistent spatial origin for the boundary layer, the turbulence was 'tripped' by a $3 \mathrm{~mm}$ diameter rod spanning the bed at the test section entrance.

A plate (described in the previous subsection) was set on the floor of the flume with the long axis of the plate parallel to the flow direction. The plate was placed along the centerline of the flume with its upstream edge $6.25 \mathrm{~m}$ downstream from the test section entrance. A ramp $0.2 \mathrm{~m}$ in length at the upstream edge of the plate provided a smooth transition between the floor of the flume and the top surface of the plate. 

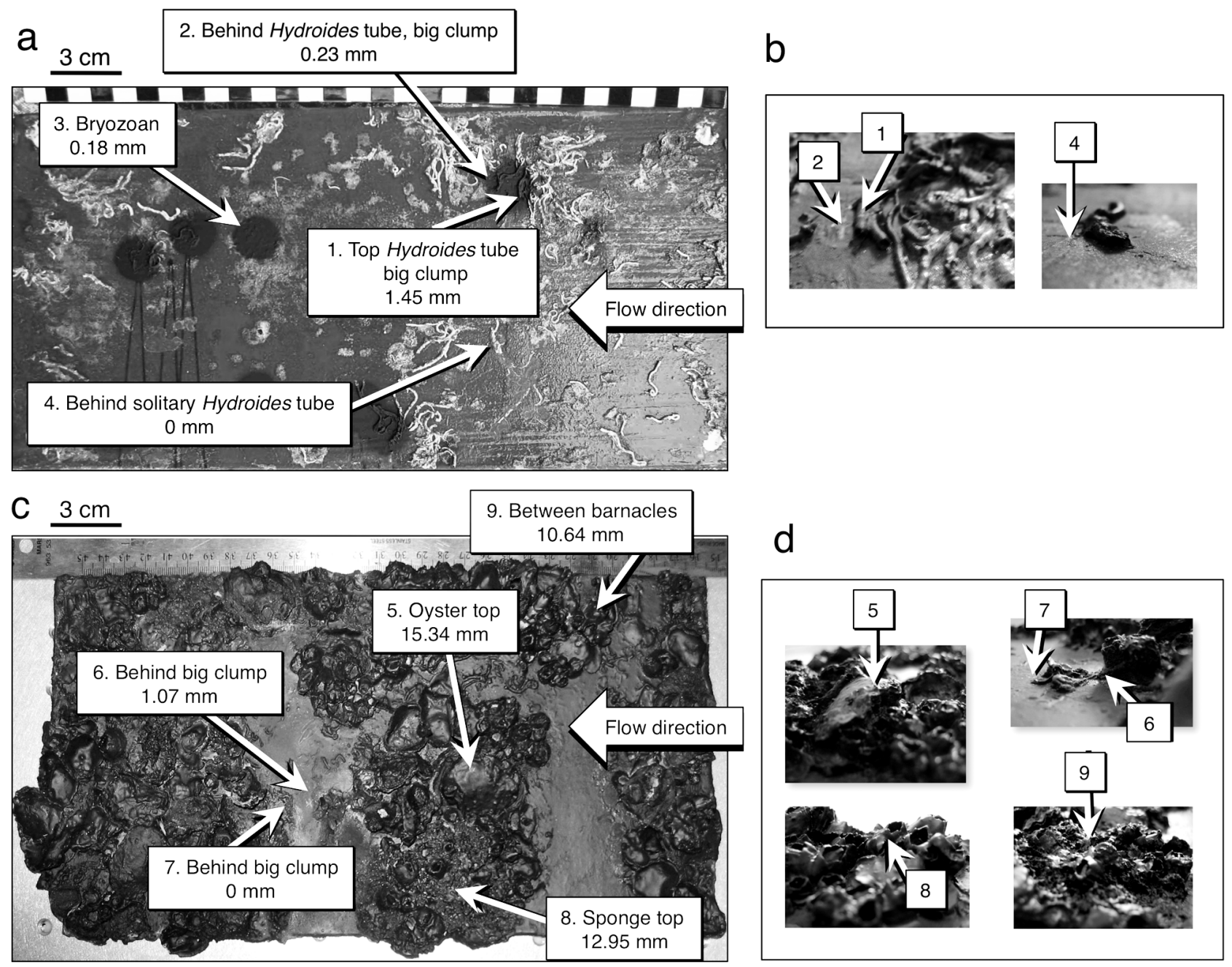

Fig. 1. Photographs of the plate with $(a, b)$ the 'early' successional stage and $(c, d)$ the late successional stage of the fouling community after being freeze-dried and painted. The points over which velocities were measured are labeled, and their heights above the floor of the flume are given $(a, c)$. The organisms with some vertical relief are shown in perspective view $(b, d)$

We used 3 different water flow rates in our experiments: 'slow' (mean free-stream velocity, $U_{\infty}=0.03 \mathrm{~m}$ $\mathrm{s}^{-1}$ ) was typical of water velocities measured across our fouling plates in Pearl Harbor (Koehl \& Reidenbach 2007, Koehl \& Hadfield 2010), while 'medium' $\left(U_{\infty}=0.10 \mathrm{~m} \mathrm{~s}^{-1}\right)$ and 'fast' $\left(U_{\infty}=0.24 \mathrm{~m} \mathrm{~s}^{-1}\right)$ were chosen to represent a range of water flows measured across other fouling communities (Okamura 1984, Hunter 1988, Schabes 1992). Fig. 2 shows vertical profiles of the mean streamwise velocities for each of the 3 flow rates over the 'smooth' plate, and Table 1 gives some characteristics of the velocity profiles for these baseline cases.

In some experiments we incorporated surface waves into the currents in the flume using a wave plunger $(1.25 \mathrm{~m} \times 1.25 \mathrm{~m})$ that oscillated at the free surface upstream of the test section. We used 2 types of waves in addition to the 'no waves' case. The first wave type ('wind chop') had a frequency of $0.7 \mathrm{~Hz}$ and a peak-to-trough wave height of $0.30 \mathrm{~cm}$. These waves produced velocity oscillations of approximately $0.02 \mathrm{~m} \mathrm{~s}^{-1}$ peak-to-trough at a height of $2 \mathrm{~cm}$ above the plate, corresponding to the velocity oscillations measured at the same distance from our settling plates in Pearl Harbor due to typical wind-induced chop (Koehl \& Reidenbach 2007, Koehl \& Hadfield 2010) (Fig. 3a,b). The second wave type ('ship wake') had a frequency of $0.7 \mathrm{~Hz}$ and a peak-to-trough wave height of $1.9 \mathrm{~cm}$. These waves produced velocity oscillations of $\sim 0.10 \mathrm{~m} \mathrm{~s}^{-1}$ peak-to-trough at a height of $2 \mathrm{~cm}$ above the plate, intended to simulate the flow due to the wake of a ship, similar to the flow due to 


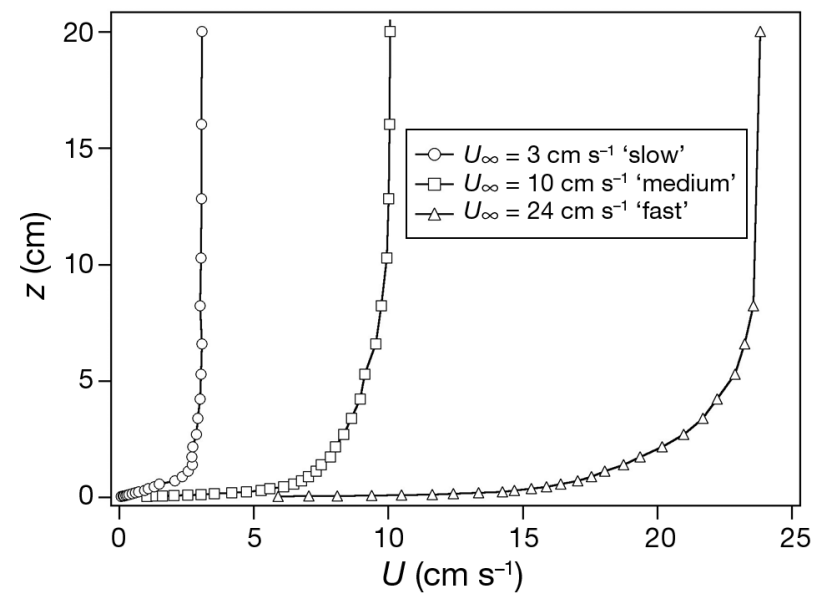

Fig. 2. Vertical profiles ( $z$ is height above the plate) of mean streamwise velocities $(U)$ over the smooth plate for the 'no waves' case in the benthic turbulence flume. The key gives the free-stream velocities $\left(U_{\infty}\right)$ for each profile

Table 1. Velocity profile characteristics for the baseline case of 'no waves' over the 'smooth' plate. The shear velocity, $u_{\tau \text {, }}$ is a measure of the total stress at the substratum, defined via $\tau_{\mathrm{w}}=\rho u_{\tau}^{2}$, where $\tau_{\mathrm{w}}$ is the total stress at the wall and $\rho$ is the water density. The shear velocity is calculated by a leastsquares fit to the law of the wall $u(z)=\left(u_{\tau} / 0.41\right) \times \ln (z \times$ $\left.u_{\tau} / v\right)+5.5$, where $v$ is the kinematic viscosity and $z$ is height above the substratum. Also given in the table are the mean streamwise velocity $U$ at a height of $0.5 \mathrm{~mm}$ from the surface of the smooth plate (the location for subsequent analysis of hydrodynamic stresses) and the mean streamwise velocity far from the bed, $U_{\infty}$

\begin{tabular}{|llll|}
\hline Velocity profile characteristics & Slow & Medium & Fast \\
\hline$u_{\tau}\left(\mathrm{m} \mathrm{s}^{-1}\right)$ & 0.002 & 0.005 & 0.01 \\
$U(z=0.5 \mathrm{~mm})\left(\mathrm{m} \mathrm{s}^{-1}\right)$ & 0.0013 & 0.014 & 0.070 \\
$U_{\infty}\left(\mathrm{m} \mathrm{s}^{-1}\right)$ & 0.030 & 0.10 & 0.24 \\
\hline
\end{tabular}

ship wakes that we measured at the same height above our plates in Pearl Harbor (Koehl 2007, Koehl \& Hadfield 2010) (Fig. 3c). Very large ships can produce wakes with longer wave periods, but we chose to focus on the typical wake period that we recorded at our Pearl Harbor site, where the waves due to ship wakes lasted about 70 to $80 \mathrm{~s}$ (Koehl 2007) and occurred about 8 times per hour (M. A. R. Koehl \& T. Cooper unpubl. data). Although these wakes occurred episodically, their durations were long relative to the time scale of a larval settling event (seconds). Hunter (1988) measured velocity oscillations due to wind chop and to ferry wakes in water flowing across fouling communities in Friday Harbor, Washington, that were similar to those we measured in Pearl Harbor for wind chop and ship wakes, respectively.
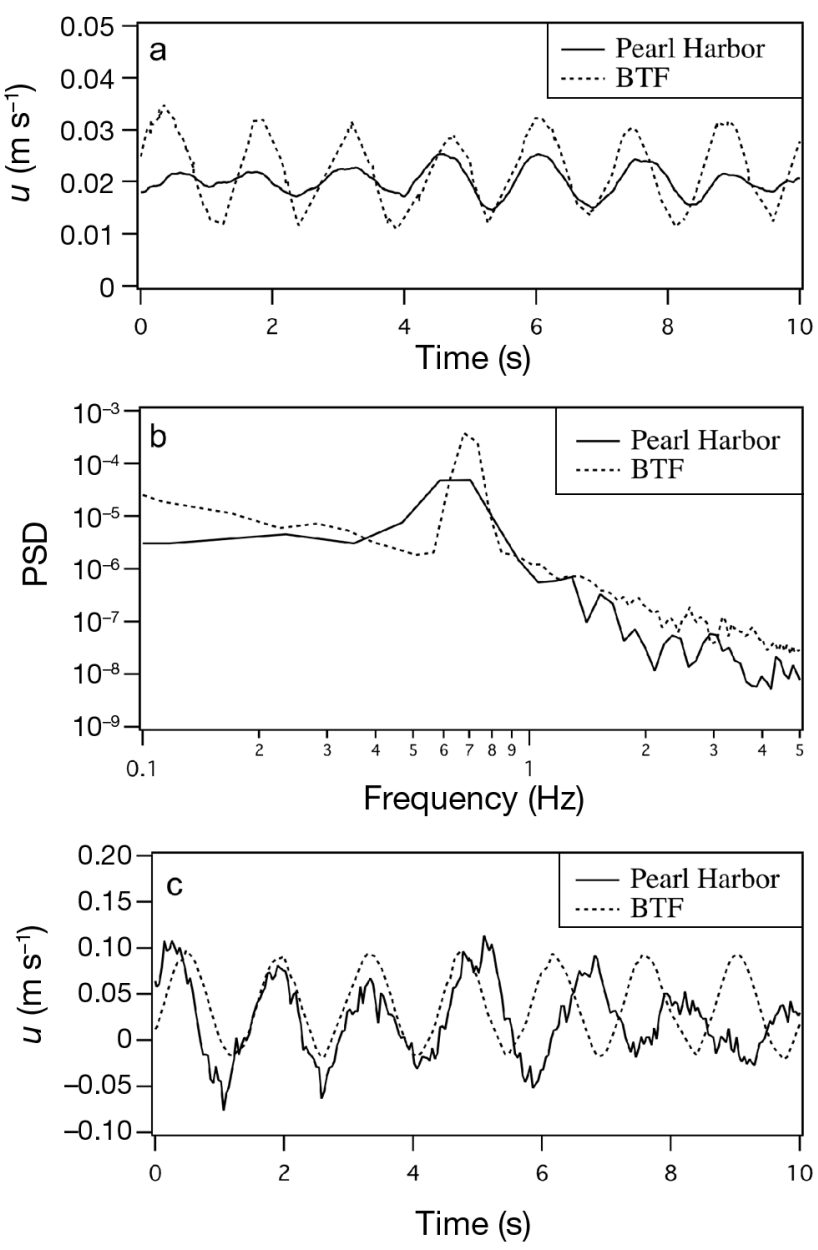

Fig. 3. (a) Plots of velocity in the streamwise direction $(u)$ as a function of time for the 'wind chop' flow condition measured at a height of $2 \mathrm{~cm}$ from the surface of a plate on which an 'early' successional stage of the fouling community was growing. Solid line shows flow measured in Pearl Harbor (using a Marsh-McBirney 523 electromagnetic flow meter); dashed line shows flow measured in the benthic turbulence flume (BTF) (using the Laser Doppler Anemometer described in 'Materials and methods'). (b) Power spectral density (PSD) plotted as a function of frequency for the flow conditions depicted (a). Solid line represents the spectrum for flow recorded in Pearl Harbor; dashed line, for flow in the BTF. The Pearl Harbor spectrum contains 20 s of velocity data, and the BTF spectrum contains $120 \mathrm{~s}$ of data. Such spectra indicate how much of the variation in velocity is due to fluctuations at different frequencies (see Bendat \& Piersol 2011). Both laboratory and field data show a peak at $0.7 \mathrm{~Hz}$, the frequency of the waves due to wind chop, and both show similar levels of turbulence. (c) Plot of velocity as a function of time for the 'ship wake' flow condition measured in Pearl Harbor (solid line) and in the BTF (dashed line) at a height of $2 \mathrm{~cm}$ from the surface of the plate with the 'early' successional stage fouling community

In flume studies of larval settlement, it is important to mimic the turbulence in the flume to the turbulence in the field (e.g. Hendriks et al. 2006). We 
matched the turbulence spectrum and waves in our flume to that of the flow measured across fouled surfaces in Pearl Harbor (e.g. Fig. 3b).

\section{Water velocity measurements}

Water velocities were measured at various locations as a function of time using a 2-component laserDoppler velocimeter (LDV). LDV measurements have been previously used to study the effect of local turbulent stresses on sediment transport (Nelson et al. 1995) and larval settlement in unidirectional water currents (Crimaldi et al. 2002), and on larval settlement on coral reefs in waves (Reidenbach et al. 2009). The measurement volume has dimensions of $0.08 \mathrm{~mm}$ in vertical and streamwise directions, and $1.2 \mathrm{~mm}$ in the spanwise direction, making it sufficiently small to resolve the stress-producing velocity fluctuations. We measured water velocities at a height of $500 \mu \mathrm{m}$ above the points indicated in Fig. 1. The $500 \mu \mathrm{m}$ location was far enough above the local substratum to provide separation between the measurement volume with the substratum, while maintaining a sufficiently high data rate for the statistical analysis that follows. Velocity records 10 to $15 \mathrm{~min}$ in duration were used to calculate the statistical nature of the stress variations at potential settlement sites.

The larvae of various animals in the fouling community range in length from several hundred microns (e.g. larvae of the oysters, barnacles, tube worms, and bryozoans) to a millimeter (e.g. ascidian tadpoles), so flow velocities measured at a height of 500 $\mu \mathrm{m}$ could be used to estimate the probability that larvae that landed on these surfaces would be swept away by stresses associated with the water flowing past the plates.

\section{Data processing}

Anchoring probabilities were calculated from the LDV velocity records. Fig. 4 shows a step-by-step probability calculation for 2 settlement sites, the resulting probabilities of which differ significantly. The left column is for the position at the top of an oyster (height $=15.34 \mathrm{~mm}$ ) in the late-stage fouling community (Position 5; Fig. 1c,d), and the right column is for the position at the encrusting bryozoan colony (height $=0.18 \mathrm{~mm}$ ) in the early-stage fouling community (Position 3; Fig. 1a,b). The data for both sites were gathered for the same flow case: 'slow' flow with the 'ship wake'. The first 2 rows of the figure $(a-d)$ show typical $60 \mathrm{~s}$ segments of the horizontal $(u)$ and vertical $(w)$ velocities as recorded by the LDV at a distance of $0.5 \mathrm{~mm}$ above each site. The local mean velocities $U$ and $W$ were subtracted from each record to give records of velocity fluctuations $u^{\prime}$ and $v^{\prime}$. Records of instantaneous Reynolds stress were calculated using Eq. (1), the magnitude of which is shown in the third row (Fig. 4e,f). The magnitude of the Reynolds stress record was used to calculate anchoring probabilities, using a method described in detail by Crimaldi et al. (2002). The stress record was partitioned into a series of 'stress lulls' when the instantaneous stress was below some critical resuspension stress $\tau_{\mathrm{R}}$ (the stress required to resuspend a settled, but unattached, larva off the substratum back into the overlaying flow). A statistical analysis of the stress lull lengths gives an anchoring probability for any given resuspension stress, given an assumed required anchoring time, $t_{\mathrm{a}}$. The process was then repeated for a range of resuspension stresses, giving an anchoring probability curve as a function of resuspension stress as shown in the fourth row of Fig. $4 \mathrm{~g}, \mathrm{~h}$. The dotted lines in Fig. $4 \mathrm{~g}$, h show the resuspension stress that results at a $50 \%$ anchoring probability, designated $\tau_{50}$. The process was repeated for a range of assumed required anchoring times, and the resuspension stress that produces $\tau_{50}$ was plotted as a function of the required anchoring time $\left(t_{\mathrm{a}}\right)$ in the fifth row (Fig. $4 \mathrm{i}, \mathrm{j}$ ). In most of our reported results, we used an assumed anchoring time of $t_{\mathrm{a}}=1 \mathrm{~s}$.

Confidence intervals for $\tau_{50}$ data were calculated using a Monte-Carlo resampling scheme (with data replacement), often referred to as a bootstrap technique (e.g. Efron 1982, Bendat \& Piersol 2011). The LDV velocity records used to calculate $\tau_{50}$ typically contain 10000 samples for each measurement location. One-hundred smaller sub-blocks of velocities (typically 2000 points) were extracted from the original record and used to generate estimates of $\tau_{50}$, from which a mean and a standard deviation for $\tau_{50}$ were calculated. The start location of each sub-block was chosen at random, and the sub-block data were replaced into the original record before choosing the next block.

\section{RESULTS}

\section{Hydrodynamic forces on settling larvae and probability of settling}

As a measure of how difficult it is for larvae to settle at a particular spot, we have used $\tau_{50}$, which is the lar- 

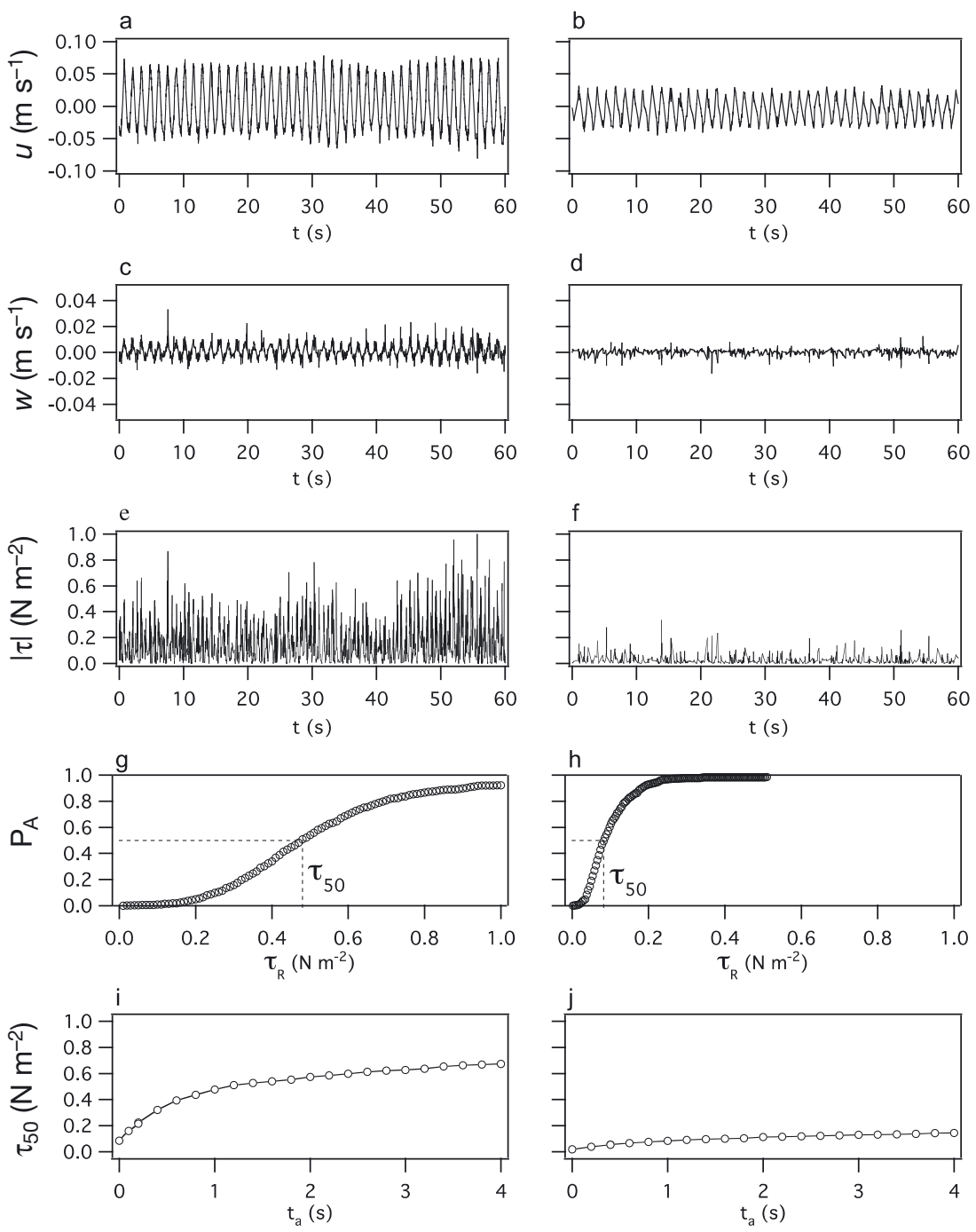

Fig. 4. Steps in the analysis sequence for 2 different locations on the early succession plate at the 'slow' flow speed with no waves. Left column is for the position at the top of an oyster (height $=15.34 \mathrm{~mm}$ ) in the late-stage fouling community (Position 5 ; Fig. 1 1 , d); the right column is for the position at the encrusting bryozoan colony (height $=0.18 \mathrm{~mm}$ ) in the early-stage fouling community (Position 3 ; Fig. $1 \mathrm{a}, \mathrm{b})$. Time histories of the $(\mathrm{a}, \mathrm{b})$ streamwise and $(\mathrm{c}, \mathrm{d})$ vertical velocities. The mean is subtracted from these 2 signals, and the magnitude of the product (when multiplied by $\rho$ ) is $(\mathrm{e}, \mathrm{f})$ the Reynolds stress magnitude. $(\mathrm{g}, \mathrm{h})$ The probability of settlement in this stress environment, as a function of resuspension stress, for a required anchoring time of $t_{\mathrm{a}}=1 \mathrm{~s}$. Dotted lines indicate the resuspension stress for $50 \%$ settling probability $\left(\tau_{50}\right)$. $(i, j)$ The variation of $\tau_{50}$ with anchoring time community on the hydrodynamic forces affecting larval settlement, we have focused on the example of larvae that take $1 \mathrm{~s}$ to adhere to the substratum after first making contact with it. For larvae that take longer to adhere, the probability of successfully settling at a spot would be lower, and, for larvae that adhere more quickly, the settlement probability would be higher (Crimaldi et al. 2002) .

\section{Effect of microhabitat on $\tau_{50}$}

The magnitudes of $\tau_{50}$ 's for positions characterized by different small-scale topography are compared in Fig. 5. Under all flow conditions, the $\tau_{50}$ 's of microhabitats on the tops of fouling organisms were significantly higher than for other positions in the fouling community. The $\tau_{50}$ 's of some microhabitats within a single fouling community (both early and late stage) were significantly different from each other, and such within-community differences were most pronounced when a community was exposed to the large waves of a ship wake. The $\tau_{50}$ 's of some positions in the earlystage fouling community were not different from those in the latestage community, indicating that local topography was more important than successional stage of the community in determining the flow forces experienced by a settling larva. The late-stage fouling community (Fig. 1c) had a greater range of sizes of roughness elements than did the early-stage community (Fig. 1a), and thus it is not surprising val attachment strength (i.e. the critical Reynolds stress required to dislodge a larva) that would yield a $50 \%$ attachment probability at a particular position (see Fig. $4 \mathrm{~g}, \mathrm{~h}$ ). Thus, the higher the $\tau_{50}$ for a given position and ambient flow condition, the more difficult it would be for larvae with a given adhesive strength to attach. In order to compare the effects of waves and of fine-scale local topography within a that the range of $\tau_{50}$ 's for the late-stage community was greater than for the early-stage community.

\section{Effect of waves on $\tau_{50}$}

When wind chop was superimposed on a unidirectional current, $\tau_{50}$ increased significantly (i.e. settle- 


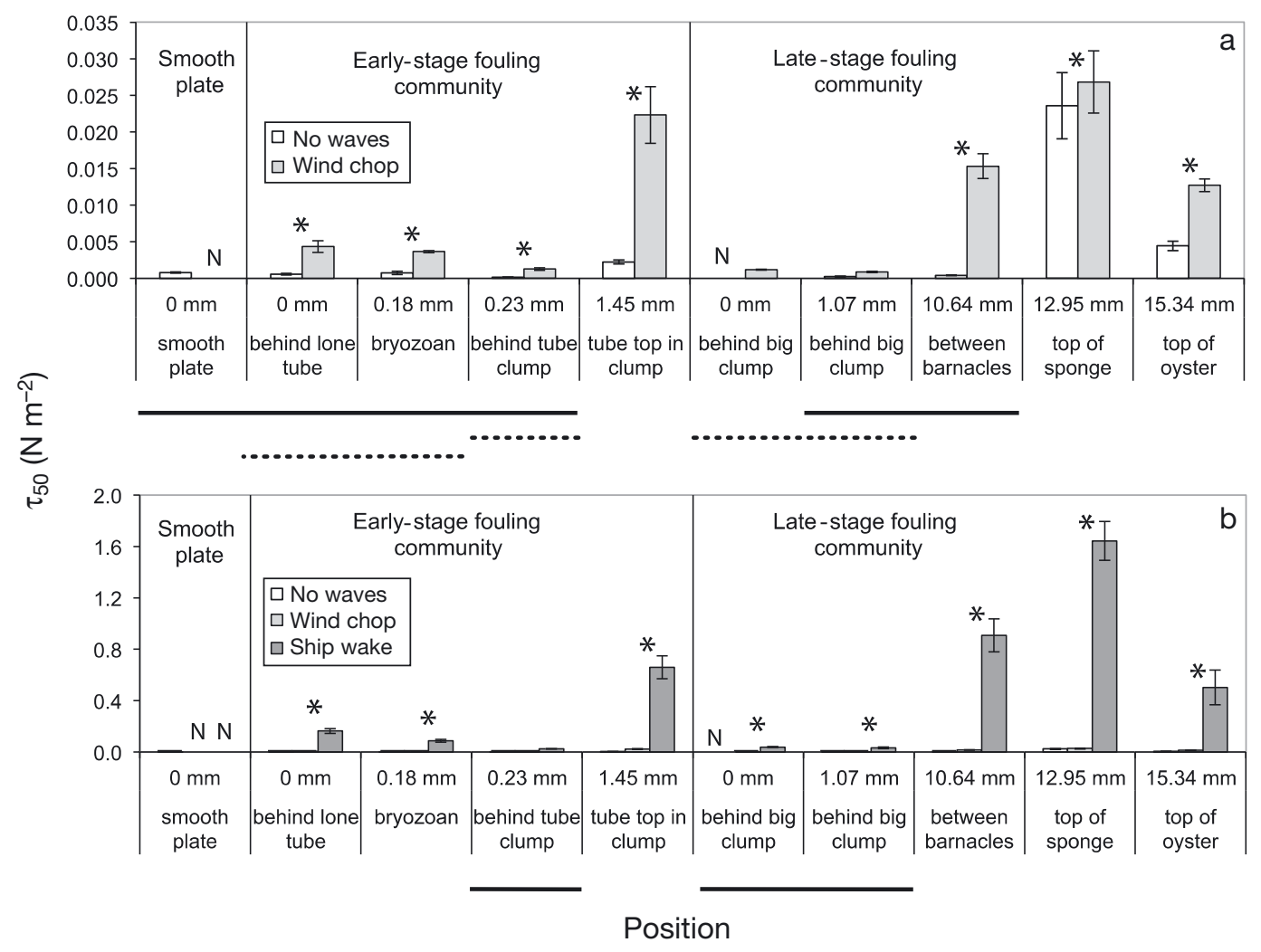

Fig. 5. Difficulty of larval attachment ( $\tau_{50}$, the critical dislodgement Reynolds stress for larvae with a probability of 0.5 of attaching successfully to a surface), plotted for various types of microhabitats within fouling communities (height of each microhabitat position above the floor of the flume is given in millimeters) exposed to different wave conditions. Error bars represent 1 standard deviation calculated with a bootstrap method (see 'Materials and methods; Data processing'). Plates with no fouling organisms, with an early-stage fouling community, and with a late-stage fouling community were exposed to the 'slow' current condition similar to that measured at our Pearl Harbor field sites (free-stream velocity, $U_{\infty}=0.030 \mathrm{~m} \mathrm{~s}^{-1}$; Fig. 2). ' $\mathrm{N}$ ' indicates cases not tested. (a) White bars show $\tau_{50}$ for the slow unidirectional current; grey bars, for the slow current plus small waves that simulate wind chop (Fig. $3 \mathrm{a}, \mathrm{b}$ ). An asterisk indicates a significant difference between the $\tau_{50}$ values for the unidirectional and the wind chop flow conditions for a particular microhabitat; horizontal lines below the graph connect microhabitats for which the $\tau_{50}$ 's are not significantly different in the unidirectional current case (solid lines) or the current plus wind chop case (dotted lines) (ANOVA, Bonferroni: significance level $5 \%, \mathrm{p}<0.0001$ ). (b) Dark grey bars show $\tau_{50}$ for the slow unidirectional current plus waves that simulate a ship wake (Fig. 3c); white bars, for the slow unidirectional flow; and light grey bars, for the slow current plus wind chop (the values for the latter 2 cases are so much smaller than for the ship wake case that the bars are not visible for some of the microhabitats at the scale of this graph). An asterisk indicates a significant difference between the $\tau_{50}$ values for the ship wake and wind chop flow conditions for a particular microhabitat; horizontal lines below the graph connect microhabitats for which the $\tau_{50}$ 's are not significantly different in the ship wake case (ANOVA, Bonferroni: significance level $5 \%, \mathrm{p}<0.0001)$

ment became more difficult) at all positions on the plate with the low-profile early successional stage of the fouling community (Fig. 5a). In contrast, the $\tau_{50}$ of a microhabitat behind a clump of tall organisms in the late-stage fouling community was unaffected by wind chop, while the $\tau_{50}$ 's of microhabitats atop large organisms were increased significantly (Fig. 5a). However, ship wakes caused significantly higher $\tau_{50}$ 's than did wind chop at most positions, including those behind the big clump in the late-stage community (Fig. 5b).

\section{Effect of current speed on $\tau_{50}$}

The effect of the ambient water current speed on $\tau_{50}$ for various microhabitats is shown in Fig. 6. In unidirectional flow, as current speed was increased, the $\tau_{50}$ 's of all the microhabitats increased significantly, but the magnitudes of the changes in $\tau_{50}$ were much smaller for microhabitats behind fouling organisms than for microhabitats on the tops of organisms or for the unfouled, smooth plate (Fig. 6a). Increasing current speed also significantly raised $\tau_{50}$ when a ship 


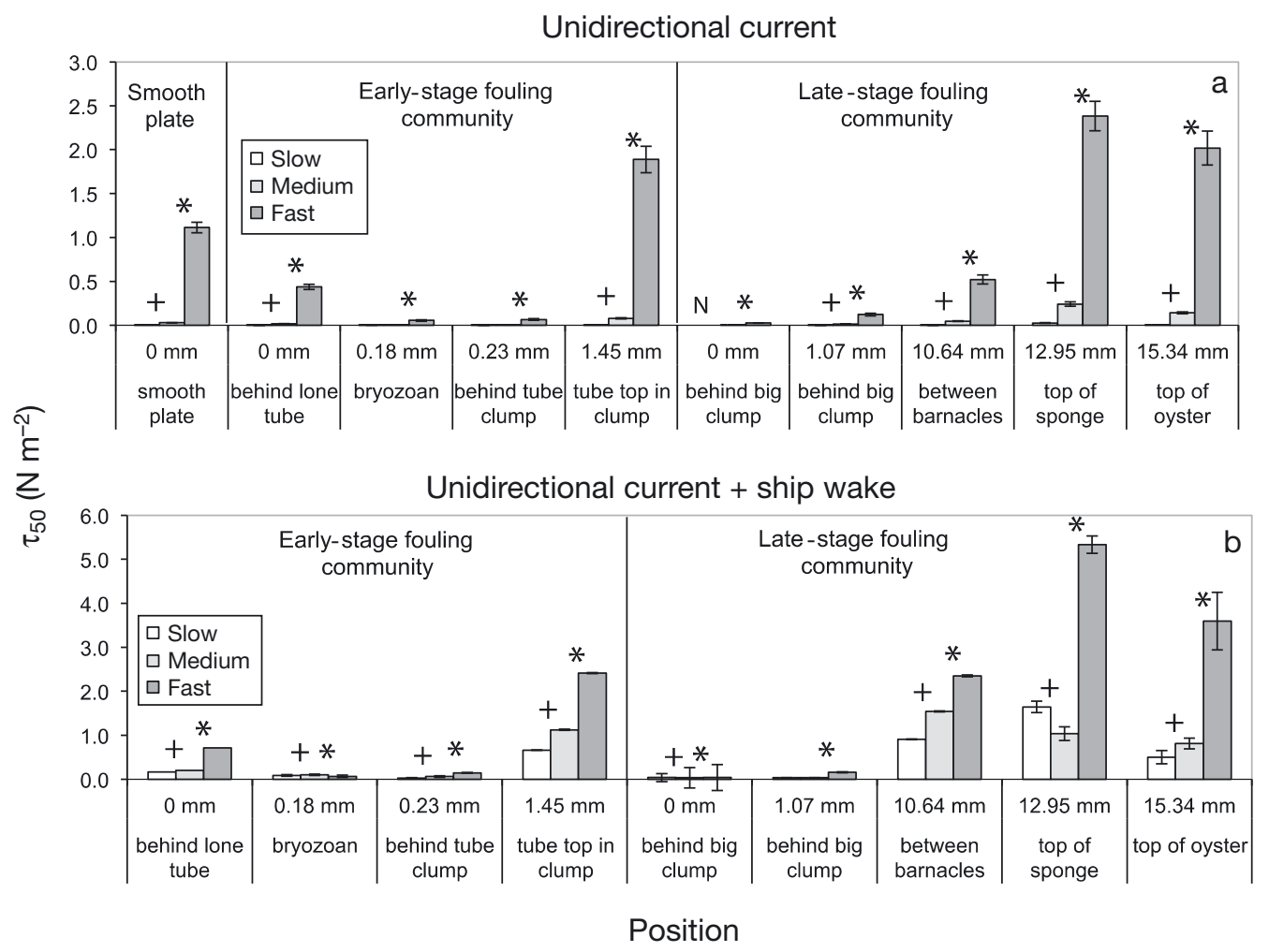

Fig. 6. Difficulty of larval attachment $\left(\tau_{50}\right)$, plotted for various types of microhabitats within fouling communities (height of each microhabitat above the fume floor is given in millimeters) exposed to different current velocities. Error bars represent 1 standard deviation calculated with a bootstrap method. White bars represent the 'slow' current (free-stream velocity, $U_{\infty}=0.03 \mathrm{~m}$ $\left.\mathrm{s}^{-1}\right)$; light grey bars, the 'medium' current $\left(U_{\infty}=0.10 \mathrm{~m} \mathrm{~s}^{-1}\right)$; and dark grey bars, the 'fast' current $\left(U_{\infty}=0.24 \mathrm{~m} \mathrm{~s}^{-1}\right)$. (a) $\tau_{50}$ for microhabitats exposed to unidirectional currents. (b) $\tau_{50}$ for microhabitats exposed to unidirectional current plus waves that simulate a ship wake. A plus sign indicates a significant difference between the $\tau_{50}$ values for the slow and medium current flow conditions for a particular microhabitat; an asterisk indicates a significant difference between the $\tau_{50}$ values for the medium and fast current conditions (ANOVA, Bonferroni: significance level $5 \%, p<0.0001$ )

wake was superimposed on the current (Fig. 6b), and the $\tau_{50}$ 's at each position were greater than in nonwavy flow.

\section{Effect of anchoring time on $\tau_{50}$}

When calculating the $\tau_{50}$ to compare different microhabitats and flow regimes, we assumed a nominal value of $1 \mathrm{~s}$ for the time required for a larva to adhere to the substratum (anchoring time, $t_{\mathrm{a}}$ ). In Fig. 7 , we show how $\tau_{50}$ varies for a range of assumed $t_{\mathrm{a}}$ values. The examples shown in Fig. 7 are for a microhabitat exposed to low stresses and for another exposed to high stresses, and show the unidirectional flow, wind chop, and ship wake cases when the ambient current was slow. In a unidirectional current, the value of $\tau_{50}$ increased monotonically with $t_{\mathrm{a}}$. In the cases with waves due to wind chop or to a ship wake, changes in anchoring time had greater effects on $\tau_{50}$ when $t_{\mathrm{a}}$ was lower than the wave frequency than when $t_{\mathrm{a}}$ 's were longer than the wave period.

\section{Importance of instantaneous stresses}

Many studies of particle or larval transport in a benthic boundary layer characterize the flow using various measures of mean stress along the substratum (e.g. reviewed in Koehl 2007, Friedrichs et al. 2009, Larsson et al. 2010, Taylor et al. 2010). In contrast, $\tau_{50}$ is a statistical measure of resuspension stress that is calculated based on the temporal patterns of instantaneous Reynolds stresses recorded at a location where the peak stresses are sometimes several orders of magnitude larger than the local mean stress and where the durations of periods of low stress relative to larval anchoring times are critical (Crimaldi et al. 2002). To ascertain whether consideration of these instantaneous processes affected predictions of larval 

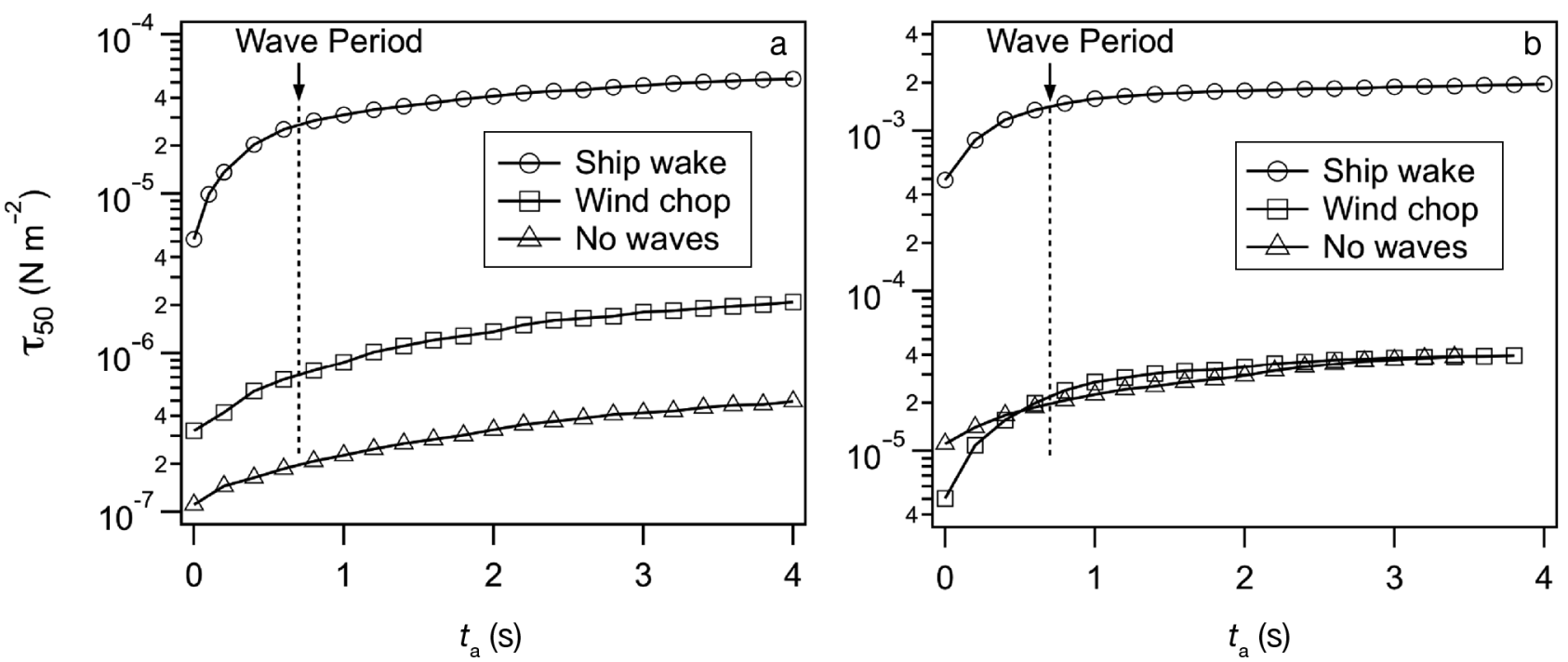

Fig. 7. Calculated values of $\tau_{50}$ for anchoring times $t_{\mathrm{a}}$ ranging from 0 to $4 \mathrm{~s}$. Results are shown for all 3 wave treatments. (a) Data for the the 'slow' flow case $\left(U_{\infty}=0.10 \mathrm{~m} \mathrm{~s}^{-1}\right)$ for the position (height $=1.07 \mathrm{~mm}$ ) behind the big clump in the late-stage fouling community (Position 6; Fig. 1c,d). (b) Data for the 'slow' flow case $\left(U_{\infty}=0.10 \mathrm{~m} \mathrm{~s}^{-1}\right.$ ) for the position (height $\left.=12.95 \mathrm{~mm}\right)$ at the top of the sponge in the late-stage fouling community (Position 8; Fig. 1c,d)

settlement probabilities, we compared the $\tau_{50}$ values with the mean Reynolds stress (mean $\tau$ ) values at the same positions in fouling communities (Fig. 8). When the ratio of $\tau_{50}$ to mean $\tau$ is $>1$, the probability of settlement is smaller than would be predicted based on the mean stress. For every microhabitat and every flow condition tested, $\left[\tau_{50} /(\right.$ mean $\left.\tau)\right]>1$. We found that the over-estimation of settlement probability by using mean $\tau$ rather than $\tau_{50}$ was most pronounced in rapid currents. The term $\left[\tau_{50} /(\right.$ mean $\left.\tau)\right]$ was not a linear function of current velocity but was affected by waves. Furthermore, $\left[\tau_{50} /(\right.$ mean $\left.\tau)\right]$ varied between microhabitats, and the effect on this ratio of changing flow conditions also differed between microhabitats.

\section{DISCUSSION}

\section{Turbulence, waves, and instantaneous stresses}

Although high instantaneous shear stresses occur along surfaces exposed to turbulent water flow as eddies sweep through the boundary layer (e.g. Eckman et al. 1990, Abelson \& Denny 1997, Crimaldi et al. 2002, Reidenbach et al. 2009), most studies of the effects of water movement on larval settlement have focused on average aspects of the flow, such as mean velocity, volume flow rate, or boundary shear velocity (e.g. reviewed in Koehl 2007, Larsson et al. 2010, Taylor et al. 2010). In contrast we used records of instantaneous stresses on the scale of larvae $(500 \mu \mathrm{m}$ from surfaces) at potential settlement sites within fouling communities to calculate $\tau_{50}$ (the larval attachment stress that would result in a $50 \%$ anchoring probability) to assess the effects of ambient flow conditions on the likelihood of larval settlement. For larvae with a given anchoring time, we found that the probability of attaching to the substratum calculated using instantaneous stresses can be much lower than that calculated using the mean stress for the same location and flow case. Furthermore, the degree to which settlement probability is over-estimated by using mean rather than instantaneous stresses differs between microhabitats. This over-estimation does not vary linearly with free-stream current velocity or peak velocity in waves. Furthermore, in some microhabitats the rank order of the current speeds at which settlement probabilities are most badly over-estimated changes if waves are superimposed on the current (e.g. bryozoan in Fig. 8).

Using the $\tau_{50}$ predictor to compare the larval settlement probabilities in different microhabitats and flow conditions, we determined that the decrease in larval attachment probability that accompanies an increase in the current speed is non-linear. Furthermore, we learned that if the oscillatory flow associated with wind chop or ship wakes is superimposed on the ambient current, the decrease in larval settlement probability can be profound and can differ greatly between different microhabitats within a community. Because wave action is an important feature of the water flow in most shallow coastal habi- 


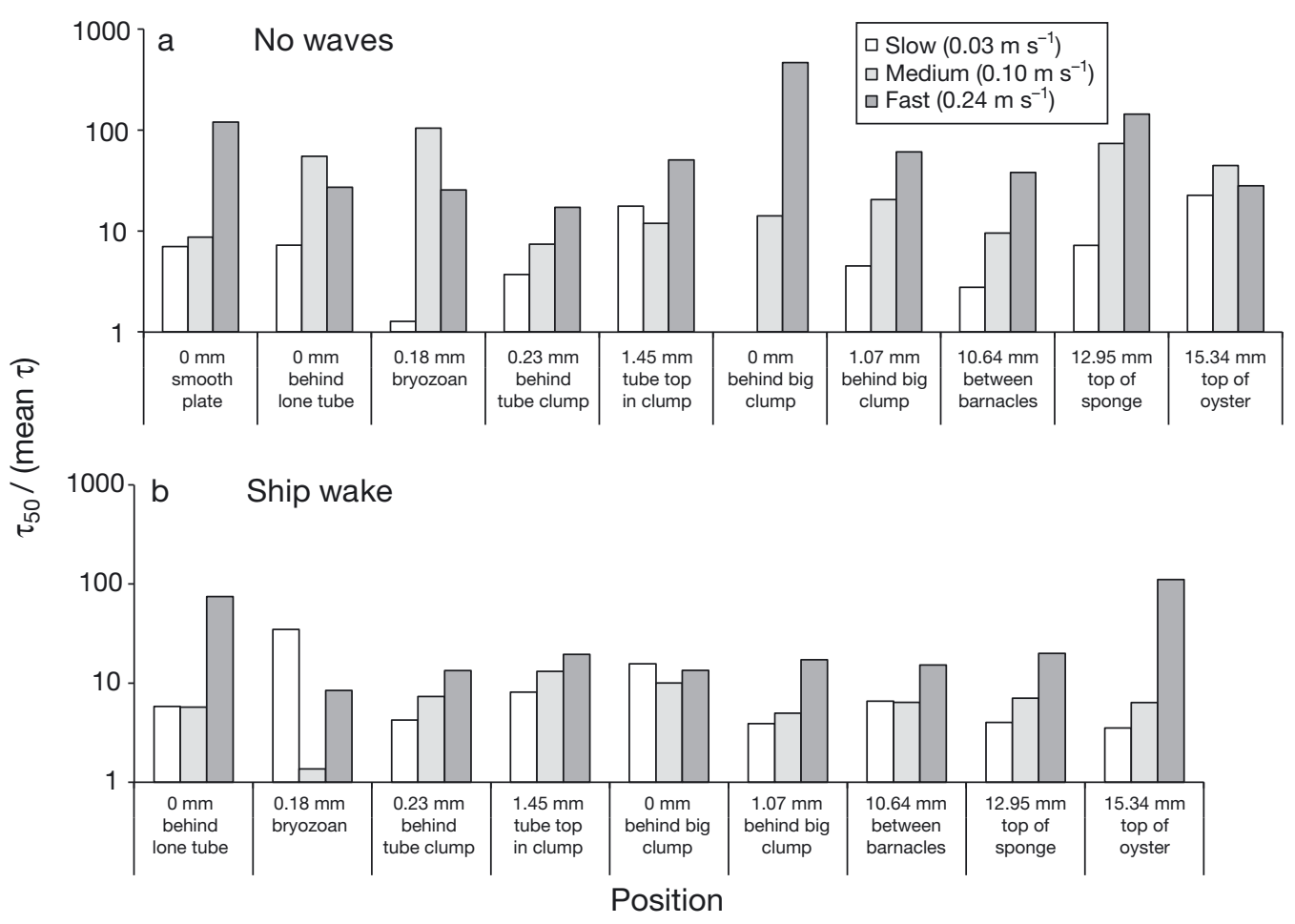

Fig. 8. (a) Ratio of $\tau_{50}$ to the mean Reynolds stress ( $\tau_{\text {mean }}$ ) plotted for positions on a plate with an early-stage fouling community and a plate with a late-stage fouling community when exposed to slow (white bars), medium (grey bars), or fast (black bars) current velocities. When $\left[\tau_{50} /(\right.$ mean $\left.\tau)\right]>1$, the probability of settlement is smaller than would be predicted based on the mean stress. (b) As in (a) but when exposed to waves that simulated a ship wake superimposed on the 3 current velocities

tats, our results point out the importance of including waves in future studies of water flow effects on larval settlement.

We found that stresses that would be experienced by larvae settling onto surfaces in fouling communities were highly episodic, with large stress events (often several orders of magnitude greater than the mean) disrupting relatively long periods of low stresses. Crimaldi et al. (2002) showed for beds of uniformly distributed clams exposed to unidirectional turbulent water flow that the time required for larvae to anchor themselves to the substratum relative to the time scales of stress fluctuations in the flow affected larval settlement probabilities. For the more topographically complex fouling communities examined in this study, we also found that larvae that could adhere quickly to a surface had higher probabilities of settling than did larvae that took longer to stick. Furthermore, by superimposing wind chop or a ship wake on the ambient current, we discovered that differences in anchoring time had greater effects on settlement probabilities if the time required for a larva to anchor was shorter than the wave period than if anchoring time was longer than the wave period. The importance to settlement probability of intermittent high stresses and of larval anchoring time suggests that measurements of larval attachment strength done in steady-state shear or with steady force application (e.g. Eckman et al. 1990, Koehl \& Hadfield 2004, Haesaerts et al. 2005, Bailly et al. 2009) should be replaced by measurements exposing larvae on surfaces to brief, realistic bursts of rapid water flow.

\section{Flow microhabitats in benthic communities}

Microscopic larvae (lengths of a few hundred micrometers) settling into a benthic community of macroscopic organisms are small relative to the topography produced by the organisms already living on the surface (scales of millimeters to centimeters). We used fouling communities to explore how fine-scale local topography within complex assemblages of attached organisms can affect the hydrodynamic stresses experienced by microscopic larvae that have landed in different microhabitats within a benthic community. We found that settling larvae in 
rugose fouling communities can experience hydrodynamic stresses lower or higher than they do on flat surfaces. Microhabitats on the tops of benthic organisms not only experience the highest stresses, but also are the most sensitive to changes in ambient water flow. Our results indicate that local topography is more important than successional stage of a fouling community in determining the hydrodynamic stresses experienced by a larva.

By focusing on water flow on the spatial scale relevant to settling larvae, we found that some positions within a community are buffered from changes in ambient flow conditions more than others. Furthermore, positions within a community that are protected from rapid flow in unidirectional currents can become vulnerable to big stresses in waves. Therefore, conclusions drawn from flume studies done in unidirectional flow about patterns of larval settlement might be misleading if applied to habitats where wind chop, ship wakes, or waves occur.

Our finding that flow microhabitats within communities of organisms can be quite different from the free-stream flow across a site is consistent with the results of earlier studies of the effects of aggregations of organisms on water flow. For example, field measurements revealed that individuals within aggregations of sea anemones (Koehl 1977) and mussels (Wethey 2004) were protected by their neighbors from high hydrodynamic forces. Similarly, water flow within coral reefs (Reidenbach et al. 2009) and aggregations of snails (Moulin et al. 2007) was slower than flow over the tops of theses groups of animals. Other studies have shown that the spacing between biological roughness elements (e.g. worm tubes, barnacles) affects the water flow between them, as well as where ambient water currents deposit particles or sweep them off the substratum (Eckman 1985, Johnson 1990, Thomason et al. 1998, Fingerut et al. 2011).

The presence and composition of a community of organisms on a surface can affect larval settlement and survivorship in ways other than via effects on water flow (e.g. reviewed by Koehl 2007, Prendergast et al. 2008, 2009). For example, the positions where larvae settle on rugose surfaces may be due to their preference for shade (Maldonado \& Uriz 1998), or to their exploratory behavior on, or ability to adhere to different surface textures (Prendergast et al. 2008, Scardino et al. 2009). Furthermore, chemical cues from particular species on the substratum can induce larvae to settle on or reject specific sites (e.g. reviewed in Woodin 1991, Hadfield \& Paul 2001, Hadfield \& Koehl 2004, Manriquez \& Castilla 2007, Dobretsov \& Wahl 2008, Prendergast et al. 2008).
Some studies have distinguished between biological and physical factors by comparing larval settlement onto artificial roughness elements with settlement onto assemblages of real benthic organisms (e.g. Wethey 1986, Wright \& Boxshall 1999, Czarnoleski et al. 2004). The effects of benthic organisms or roughness elements on recruitment can also be due to postsettlement survivorship (reviewed by Eckman 1990, Walters et al. 1997, Schiel 2004). For example, newly settled juveniles in depressions or grooves can be in refuges from bulldozing or predation by grazing animals (e.g. Wethey 1984, Walters \& Wethey 1991), or may be protected from drying or overheating (e.g. Maldonado \& Uriz 1998). Several authors have argued that natural selection should favor larvae that choose to settle in microhabitats where their postsettlement survival is enhanced (e.g. Maldonado \& Uriz 1998, Buschbaum 2001). These previous investigations focusing on biological factors affecting settlement and recruitment, as well as the present flow study, all reveal the importance of focusing on the environment on the scale of the larva.

Benthic marine algae disperse via microscopic spores that are transported by ambient currents and colonize surfaces on which they land and attach. Substratum topography and chemistry, and the duration of spore contact, affect the adhesive strength of algal spores (e.g. reviewed by Fletcher \& Callow 1992, Granhag et al. 2004). The attachment strength of algal spores is typically measured using turbulent unidirectional flow (e.g. Charters et al. 1973, Ucar et al. 2010, Evariste et al. 2012) or a water jet (e.g. Christie et al. 1970, Finlay et al. 2002, Granhag et al. 2004, Cassé et al. 2007). Our results about the importance of waves and the temporal patterns of intermittency of flow stresses in different microhabitats on rugose benthic substrata should also be applicable to spore settlement.

While investigating fine-scale water flow across surfaces in complex fouling communities, we not only learned the importance of assessing hydrodynamic stresses on the fine spatial and temporal scales that affect microscopic larvae as they settle onto surfaces in a community, but also of including waves, which typify water flow in many shallow coastal habitats.

Acknowledgements. This research was supported by National Science Foundation Grant 10S-0842685, Office of Naval Research Grant N00014-03-1-0079, and the Virginia G. and Robert E. Gill Chair (to M.A.R.K.), and by National Science Foundation Grant 0348855 (to J.P.C.). We thank M. Hadfield and B. Neved at the Kewalo Marine Laboratory, University of Hawaii, for providing us with fouled plates and helpful advice. 


\section{LITERATURE CITED}

Abelson A, Denny MW (1997) Settlement of marine organisms in flow. Annu Rev Ecol Syst 28:317-339

> Abelson A, Weihs D, Loya Y (1994) Hydrodynamic impediments to settlement of marine propagules, and adhesivefilament solutions. Limnol Oceanogr 39:164-169

Allen JRL (1985) Principles of physical sedimentology. Allen \& Unwin, Boston, MA

Bailly P, Grosjean P, Flamming P (2009) Measurement of the attachment strength of brachiolaria larvae and metamorphic individuals in the sea star Asterina gibbosin by a centrifugation method. J Exp Mar Biol Ecol 372:82-90

Bendat JS, Piersol AG (2011) Random data: analysis and measurement procedures. John Wiley \& Sons, Hoboken, NJ

Buschbaum C (2001) Selective settlement of the barnacle Semibalanus balanoides (L.) facilitates its growth and reproduction on mussel beds in the Wadden Sea. Helgol Mar Res 55:128-134

> Butman CA (1990) Sediment-trap experiments on the importance of hydrodynamical processes in distributing settling invertebrate larvae in near-bottom waters. J Exp Mar Biol Ecol 134:37-88

Carpenter P (1997) The right sort of roughness. Nature 388: 713-714

Cassé F, Ribeiro E, Ekin A, Webster DC, Callow JA, Callow $\mathrm{ME}$ (2007) Laboratory screening of coating libraries for algal adhesion. Biofouling 23:267-276

Chabot R, Bourget E (1988) Influence of substratum heterogeneity and settled barnacle density on the settlement of cypris larvae. Mar Biol 97:45-56

> Charters AC, Neushul M, Coon D (1973) Effect of water motion on algal spore adhesion. Limnol Oceanogr 18: 884-896

Christie AO, Evans LV, Shaw M (1970) Studies of the ship fouling alga Enteromorpha. II. The effect of certain enzymes on the adhesion of zoospores. Ann Bot (Lond) 34:468-482

> Crimaldi JP, Thompson JK, Rosman JH, Lowe RJ, Koseff JR (2002) Hydrodynamics of larval settlement: the influence of turbulent stress events at potential recruitment sites. Limnol Oceanogr 47:1137-1151

Crisp DJ (1955) The behavior of barnacle cyprids in relation to water movement over a surface. J Exp Biol 32:569-590

> Czarnoleski M, Michalczyk L, Pajdak-Stos A (2004) Substrate preference in settling zebra mussels Dreissena polymorpha. Arch Hydrobiol 159:263-270

Denny MW (1988) Biology and the mechanics of the waveswept environment. Princeton University Press, Princeton, NJ

> Denny MW, Shibata MF (1989) Consequences of surf-zone turbulence for settlement and external fertilization. Am Nat 134:859-889

> Dobretsov S, Wahl M (2008) Larval recruitment of the blue mussel Mytilus edulis: the effect of flow and algae. J Exp Mar Biol Ecol 355:137-144

> Eckman JE (1985) Flow disruption by an animal-tube mimic affects sediment bacterial colonization. J Mar Res 43: 419-436

> Eckman JE (1990) A model of passive settlement by planktonic larvae onto bottoms of differing roughness. Limnol Oceanogr 35:887-901

> Eckman JE, Savidge WB, Gross TF (1990) Relationship between duration of cyprid attachment and drag forces associated with detachment of Balanus amphitrite cyprids. Mar Biol 107:111-118

Eckman JE, Werner FE, Gross TF (1994) Modelling some effects of behavior on larval settlement in a turbulent boundary layer. Deep-Sea Res II 41:185-208

Edwards KF, Stachowicz JJ (2011) Spatially stochastic settlement and the coexistence of benthic marine animals. Ecology 92:1094-1103

Efron B (1982) The jackknife, the bootstrap, and other resampling plans. 38. Society of Industrial and Applied Mathematics CBMS-NSF Monographs, Capital City Press, Montpelier, VT

Evariste E, Gachon CMM, Callow ME, Callow JA (2012) Development and characteristics of an adhesion bioassay for ectocarpoid algae. Biofouling 28:15-27

Fingerut JT, Hart DD, Thomson JR (2011) Larval settlement in benthic environments: the effects of velocity and bed geometry. Freshw Biol 56:904-915

Finlay JA, Callow ME, Schultz MP, Swain GW, Callow JA (2002) Adhesion strength of settled spores of the green alga Enteromorpha. Biofouling 18:251-256

Fletcher RL, Callow ME (1992) The settlement, attachment and establishment of marine algal spores. Br Phycol J 27: 303-329

Friedrichs M, Graf G (2009) Characteristic flow patterns generated by macrozoobenthic structures. J Mar Syst 75: 348-359

> Friedrichs M, Leipe T, Peine F, Graf G (2009) The impact of macrozoobenthic structures on near-bed sediment fluxes. J Mar Syst 75:336-347

Fuchs HL, Neubert MG, Mullineaux LS (2007) Effects of turbulence-mediated larval behavior on larval supply and settlement in tidal currents. Limnol Oceanogr 52: 1156-1165

> Fuchs HL, Solow AR, Mullineaux LS (2010) Larval responses to turbulence and temperature in a tidal inlet: Habitat selection by dispersing gastropods? J Mar Res 68: 153-188

Ghisalberti M (2009) Obstructed shear flows: similarities across systems and scales. J Fluid Mech 641:51-61

Granhag LM, Finlay JA, Jonsson PR, Callow JA (2004) Roughness-dependent removal of settled spores of the green alga Ulva (syn. Enteromorpha) exposed to hydrodynamic forces from a water jet. Biofouling 20:117-122

Grant WD, Madsen OS (1986) Continental-shelf bottom boundary layer. Annu Rev Fluid Mech 18:265-305

Grass AJ (1971) Structural features of turbulent flow over smooth and rough boundaries. J Fluid Mech 50:233-255

Gross TF, Werner FE, Eckman JE (1992) Numerical modeling of larval settlement in turbulent bottom boundary layers. J Mar Res 50:611-642

Hadfield MG, Koehl MAR (2004) Rapid behavioral responses of an invertebrate larva to dissolved settlement cue. Biol Bull 207:28-43

Hadfield MG, Paul VJ (2001) Natural chemical cues for settlement and metamorphosis of marine invertebrate larvae. In: McClintock JB, Baker W (eds) Marine chemical ecology. CRC Press, Boca Raton, FL, p 431-461

Haesaerts D, Findlay JA, Callow ME, Callow JA, Grosjean P, Jangoux M, Flamming P (2005) Evaluation of the attachment strength of individuals of Asterina gibbosa (Asteroidea, Echinodermata) during the perimetamorphic period. Biofouling 21:229-235

Hendriks IE, van Duren LA, Herman PMJ (2006) Turbulence levels in a flume compared to the field: implications for 
larval settlement studies. J Sea Res 55:15-29

Hunter T (1988) Mechanical design of hydroids: flexibility, flow forces and feeding in Obelia longissima. $\mathrm{PhD}$ thesis, University of California, Berkeley, CA

- Hurlbut CJ (1991) Community recruitment: settlement and juvenile survival of seven co-occurring species of sessile marine invertebrates. Mar Biol 109:507-515

> Johnson AS (1990) Flow around phoronids: consequences of a neighbor to suspension feeders. Limnol Oceanogr 35: 1395-1401

Jonsson PR, Berntsson KM, Larsson AI (2004) Linking larval supply to recruitment: flow-mediated control of initial adhesion of barnacle larvae. Ecology 85:2850-2859

Keough MJ, Downes BJ (1982) Recruitment of marine invertebrates: the role of active larval choices and early mortality. Oecologia 54:348-352

Kobak J (2005) Recuitment and distribution of Dreissena polymorpha (Bivalva) on substrates of different shape and orientation. Int Rev Hydrobiol 90:159-170

Koehl MAR (1977) Effects of sea anemones on the flow forces they encounter. J Exp Biol 69:87-105

Koehl MAR (2007) Mini review: hydrodynamics of larval settlement into fouling communities. Biofouling 23: 357-368

Koehl MAR (2010) How does morphology affect performance in variable environments? In: Grant PR, Grant B (eds) In search of the causes of evolution. From field observations to mechanisms. Princeton University Press, Princeton, NJ, p 177-191

Koehl MAR, Hadfield MG (2004) Soluble settlement cue in slowly moving water within coral reefs induces larval adhesion surfaces. J Mar Syst 49:75-88

Koehl MAR, Hadfield M (2010) Hydrodynamics of larval settlement from a larva's point of view. Integr Comp Biol 50: 539-551

- Koehl MAR, Reidenbach MA (2007) Swimming by microscopic organisms in ambient water flow. Exp Fluids 43: 755-768

Koehl MAR, Strother JA, Reidenbach MA, Koseff JR, Hadfield MG (2007) Individual-based model of larval transport to coral reefs in turbulent, wave-driven flow: behavioral responses to dissolved settlement inducer. Mar Ecol Prog Ser 335:1-18

Krogstad P, Anotnia R, Browne L (1992) Comparison between rough- and smooth-wall turbulent boundary layers. J Fluid Mech 245:599-617

Larsson AI, Jonsson PR (2006) Barnacle larvae actively select flow environments supporting post-settlement growth and survival. Ecology 87:1960-1966

> Larsson AI, Mattsson-Thorngren L, Granhag LM, Berglin M (2010) Fouling-release of barnacles from a boat hull with comparison to laboratory data of attachment strength. J Exp Mar Biol Ecol 392:107-114

LeTourneux F, Bourget E (1988) Importance of physical and biological settlement cues used at different spatial scales by the larvae of Semibalanus balanoides. Mar Biol 97: $57-66$

Ligrani PM (1989) Structure of turbulent boundary layers. In: Cheremisinoff NP (ed) Encyclopedia of fluid mechanics. Gulf Professional Publishing, Houston, TX, p 121-187

Lillis A, Snelgrove PVR (2010) Near-bottom hydrodynamic effects on postlarval settlement in the American lobster Homarus americanus. Mar Ecol Prog Ser 401: 161-172
Lindegarth M, Jonsson PR, Andre C (2002) Physical and numerical modeling of the role of hydrodynamic processes on adult-larval interactions of a suspensionfeeding bivalve. J Mar Res 60:499-516

Maldonado M, Uriz MJ (1998) Microrefuge exploitation by subtidal encrusting sponges: patterns of settlement and post-settlement survival. Mar Ecol Prog Ser 174:141-150

- Manriquez PH, Castilla JC (2007) Roles of larval behavior and microhabitat traits in determining spatial aggregations in the ascidian Pyura chilensis. Mar Ecol Prog Ser 332:155-165

Miron G, Bourget E, Archambault P (1996) Scale of observation and distribution of adult conspecifics: their influence in assessing passive and active settlement mechanisms in the barnacle Balanus crenatus (Brugiere). J Exp Mar Biol Ecol 150:131-147

Miron G, Walters LJ, Tremblay R, Bourget E (2000) Physiological condition and barnacle larval behavior: a preliminary look at the relationship between TAG/DNA ratio and larval substratum exploration in Balanus ampritrite. Mar Ecol Prog Ser 198:303-310

> Moulin FY, Guizien K, Thouzeau G, Chapalain G, Millemers $\mathrm{K}$, Bourg C (2007) Impact of an invasive species, Crepidula fornicata, on the hydrodynamics and transport properties of the benthic boundary layer. Aquat Living Resour 20:15-31

> Mulhearn PJ, Finnigan JJ (1978) Turbulent flow over a very rough, random surface. Boundary-Layer Meteorol 15: 109-132

Mullineaux LS, Butman CA (1991) Initial contact, exploration, and attachment of barnacle (Balanus amphitrite) cyprids settling in flow. Mar Biol 110:93-103

Nelson JM, Shreve RL, McLean SR, Drake TG (1995) Role of near-bed turbulence structure in bed-load transport and bed form mechanics. Water Resour Res 31:2071-2086

Okamura B (1984) The effects of ambient flow velocity, colony size, and upstream colonies on the feeding success of Bryozoa. I. Bugula stolonifera (Ryland), an arborescent species. J Exp Mar Biol Ecol 83:179-193

Ólafsson EB, Peterson CH, Ambrose WG Jr (1994) Does recruitment limitation structure populations and communities of macro-invertebrates in marine soft sediments: the relative significance of pre- and post-settlement processes. Oceanogr Mar Biol Annu Rev 32:65-109

Pernet F, Tremblay R, Bourget E (2003) Settlement success, spatial pattern and behavior of mussel larvae Mytilus spp. in experimental 'down-welling' systems of varying velocity and turbulence. Mar Ecol Prog Ser 260:125-140

Prendergast GS, Zurn CM, Bers AV, Head RM, Hansson LJ, Thomason JC (2008) Field-based observations of wild barnacle cyprid behaviour in response to textural and chemical settlement cues. Biofouling 24:449-459

> Prendergast GS, Zurn CM, Bers AV, Head RM, Hansson LJ, Thomason JC (2009) The relative magnitude of the effects of biological and physical settlement cues for cypris larvae of the acorn barnacle, Semibalanus balanoides L. Biofouling 25:35-44

Reidenbach MA, Koseff JR, Koehl MAR (2009) Hydrodynamic forces on larvae affect their settlement on coral reefs in turbulent, wave-driven flow. Limnol Oceanogr 54:318-330

Rittschof D, Sin TM, Teo SLM, Coutinho R (2007) Fouling in natural flows: Cylinders and panels as collectores of particles and barnacle larvae. J Exp Mar Biol Ecol 348: 85-96 
Scardino AJ, Hudleston D, Peng Z, Paul NA, de Nuys R (2009) Biomimetic characterisation of key surface parameters for the development of fouling resistant materials. Biofouling 25:83-93

Schabes M (1992) Mechanical consequences of the association between the solitary ascidian, Styela clava Herdman, 1881, and its epibiota. MS thesis, University of California, Berkeley, CA

Schiel DR (2004) The structure and replenishment of rocky shore intertidal communities and biogeographic comparisons. J Exp Mar Biol Ecol 300:309-342

Stevens CL, Taylor DI, Delaux S, Smith MJ, Schiel DR (2008) Characterisation of wave-influenced macroalgal propagule settlement. J Mar Syst 74:96-107

Sutherland JP, Karlson RH (1977) Development and stability of the fouling community at Beaufort, North Carolina. Ecol Monogr 47:425-446

Taylor D, Delaux S, Stevens C, Nokes R, Schiel D (2010) Settlement rates of macroalgal propagules: cross-species comparisons in a turbulent environment. Limnol Oceanogr 55:66-76

Thomason JC, Hills JM, Clare AS, Neville A, Richardson M (1998) Hydrodynamic consequences of barnacle colonization. Hydrobiologia 375/376:191-201

Ucar IO, Cansoy CE, Erbil HY, Pettitt ME, Callow ME, Callow JA (2010) Effect of contact angle hysteresis on the removal of the sporelings of the green alga Ulva from the fouling-release coatings synthesized from polyolefin polymers. Biointerphases 5:75-84

Underwood AJ (2004) Landing on one's foot: small-scale topographic features of habitat and the dispersion of juvenile intertidal gastropods. Mar Ecol Prog Ser 268: 173-182

Walters LJ (1992a) Field settlement locations on subtidal marine hard substrata: Is active larval exploration

Editorial responsibility: Steven Morgan,

Bodega Bay, California, USA involved? Limnol Oceanogr 37:1101-1107

> Walters LJ (1992b) Postsettlement success of the arborescent bryozoan Bugula neritina (L) - the importance of structural complexity. J Exp Mar Biol Ecol 164:55-71

$>$ Walters LJ, Wethey DS (1991) Settlement, refuges, and adult body form in colonial marine invertebrates: a field experiment. Biol Bull 180:112-118

- Walters LJ, Wethey DS (1996) Settlement and early postsettlement survival of sessile marine invertebrates on topographically complex surfaces: the importance of refuge dimensions and adult morphology. Mar Ecol Prog Ser 137:161-171

> Walters LJ, Hadfield MG, del Carmen KA (1997) The importance of larval choice and hydrodynamics in creating aggregations of Hydroides elegans (Polychaeta: Serpulidae). Invertebr Biol 116:102-114

$>$ Walters LJ, Miron G, Bourget E (1999) Endoscopic observations of invertebrate larval substratum exploration and settlement. Mar Ecol Prog Ser 182:95-108

> Wethey DS (1984) Spatial pattern in barnacle settlement: day to day changes during the settlement season. J Mar Biol Assoc UK 64:687-698

Wethey DS (1986) Ranking of settlement cues by barnacle larvae: influence of surface contour. Bull Mar Sci 39: 393-400

Wethey DS (2004) Wave forces in the surf zone: implications for population dynamics and recruitment. Integr Comp Biol 44:664A

Woodin SA (1991) Recruitment of infauna-positive or negative cues. Am Zool 31:797-807

Wright J, Boxshall A (1999) The influence of small-scale flow and chemical cues on the settlement of two congeneric barnacle species. Mar Ecol Prog Ser 183:179-187

Zilman G, Novak J, Benayahu Y (2008) How do larvae attach to a solid in laminar flow? Mar Biol 154:1-26

Submitted: June 21, 2012; Accepted: November 21, 2012 Proofs received from author(s): March 19, 2013 